\title{
Complications of Tracheostomy
}

\author{
R. M. A. MCCLELLAND, ${ }^{*}$ F.F.A. R.C.S.
}

Brit. med. 7., 1965, 2, 567-569

Tracheostomy used to be reserved for the severely ill patient with acute respiratory obstruction. As the incidence of diphtheria declined the operation came to be performed only occasionally, particularly as the high mortality and complication rates associated with the use of tracheostomy in diphtheria were well remembered. But within the past 20 years a great change has occurred as the indications for tracheostomy have widened to include tracheal and bronchial toilet (Galloway, 1943), intermittent positive-pressure ventilation of the lungs (Lassen, 1953), protection against inhalation of foreign matter (Taylor and Austin, 1951), and reduction of dead space (Carter and Giuseffi, 1951). This increased use of tracheostomy has undoubtedly prevented many deaths from diseases which formerly were inevitably fatal. However, the former high complication rate may well have been overlooked as enthusiasm for the operation increased, and little information is now available on the incidence and types of complications of tracheostomy.

\section{Present Investigation}

A retrospective survey was therefore made, particular attention being paid to complications, of every tracheostomy carried out in the United Oxford Hospitals between 1 January 1950 and 31 December 1959. Tracheostomy performed in the course of major surgery of the larynx was excluded from this survey as the complications are often those of laryngeal disease and of surgery, and also because the term tracheostomy is not synonymous with making a tracheostome during the course of another operation.

In the decade under consideration 389 tracheostomies were carried out on 383 patients. As a background to the detailed analysis of the complications the annual increase, sex and age distribution, disease on admission to hospital, indications for, and timing of the tracheostomies are first discussed.

The number of tracheostomies rose from 8 in 1950 to 76 in 1959 (Table I)-a ninefold increase. The total number of operations performed in the United Oxford Hospitals rose from 15,000 to 17,000 over the same 10 years, and in comparison these figures emphasize the increased use of tracheostomy in recent years.

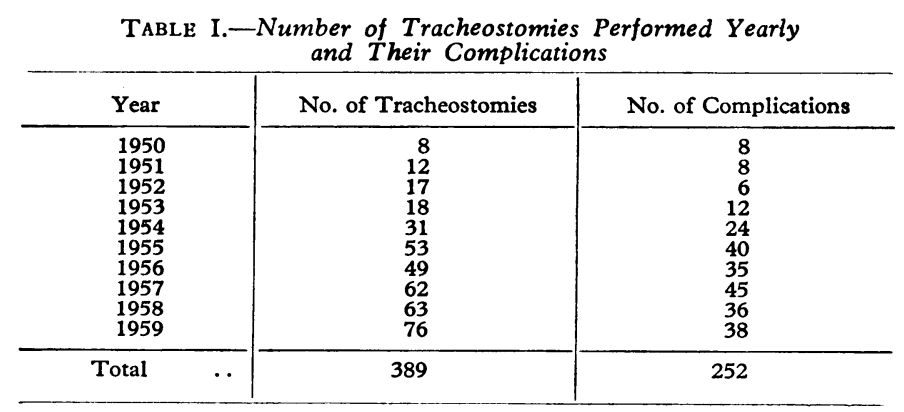

Tracheostomy was performed 266 times on male patients and 123 times on females. The reason for this sex difference was the large proportion of male patients with traumatic injuriesmainly head injuries.

The youngest patient was 13 months of age and the oldest 84 years. Table II shows the age distribution, divided into nine age-groups each of a 10-year span. Tracheostomy was carried out most frequently in patients below 10 and in those aged 50 to 69 . In children the operation was usually performed for acute upper respiratory tract obstruction caused by laryngotracheo-bronchitis or inhalation of a foreign body. No specific diseases could be implicated in the two older age-groups, but, in general terms, patients over 50 are more liable to have chronic bronchitis and malignant disease than patients below this age.

\begin{tabular}{|c|c|c|c|c|}
\hline \multicolumn{3}{|c|}{ Age group } & \multirow[b]{2}{*}{$\begin{array}{c}\text { No. of Tracheostomies } \\
51 \\
36 \\
43 \\
41 \\
47 \\
79 \\
65 \\
24 \\
3\end{array}$} & \multirow[b]{2}{*}{$\begin{array}{c}\text { No. of Complications } \\
60 \\
25 \\
18 \\
18 \\
30 \\
56 \\
34 \\
10 \\
1\end{array}$} \\
\hline $\begin{array}{c}0-9 \text { years } \\
10-19 \\
20-29 \\
30-39 \\
40-49 \\
50-59 \\
60-69 \\
70-79 \\
80+\end{array}$ & $\begin{array}{l}\because \\
\because \\
\because \\
\because \\
\because\end{array}$ & $\begin{array}{l}\ddot{ } \\
\ddot{0} \\
\ddot{0} \\
\ddot{0}\end{array}$ & & \\
\hline \multicolumn{3}{|c|}{ Total ... } & 389 & 252 \\
\hline
\end{tabular}

Though the operation was performed on patients suffering from a wide variety of diseases it was possible to assign each tracheostomy to one of six groups labelled " disease on admission to hospital." Head injuries $(110)^{1}$ formed the largest group. Respiratory disease (76) included acute laryngo-tracheobronchitis, malignant lesions involving the upper respiratory tract, chronic bronchitis, and other pulmonary diseases such as bronchial carcinoma. The peripheral nervous disease group (71) consisted of tracheostomies carried out on patients in respiratory failure admitted to the respiration unit-bulbar-spinal poliomyelitis, tetanus, polyneuritis, myasthenia gravis, barbiturate poisoning, and porphyria. The central nervous system disease group (62) included patients with cerebral tumours, brain abscesses, meningitis, and cerebrovascular accidents. Several of these tracheostomies were carried out after neurosurgical operations in patients who failed to regain consciousness. The other trauma group (42) was composed mainly of chest injuries and injury to the soft tissues of the neck adjacent to the upper respiratory tract. Patients in the small miscellaneous group (28) were often those in respiratory failure after major abdominal surgery.

The indications for tracheostomy fell into five groups. Four of these indications occurred alone-toilet (106), obstruction (84), protection (23), and ventilation (12); but the largest group consisted of mixed indications (164), which comprised various combinations of these four and included, as well, reduction of dead space (28). For example, the indications in bulbo-spinal poliomyelitis were frequently ventilation, protection, and toilet ; and, after severe chest injury, reduction of dead space and toilet.

In 89 instances tracheostomy was an emergency procedure in that it was required immediately after the decision to perform the operation had been made, but on 300 occasions it was an elective procedure.

\section{Complications}

Trivial incidents such as superficial oozing of blood from the skin-edges of the tracheostomy incision were not included as

\footnotetext{
- Senior Lecturer in Anaestbetics, Welsh National School of Medicine, Cardiff.

${ }^{1}$ Figures in parentheses refer to the number of tracheostomies.
} 
complications. Certain complications occurred on several occasions-such as displacement of the tracheostomy tubeand were counted as separate complications; but others initiated a sequence of events-segmental lobar collapse progressing to widespread bronchopneumonia-and were regarded as a single complication.

The 252 complications of the 389 tracheostomies were classified into 12 groups (Table III), as follows:

\begin{tabular}{|c|c|c|c|c|}
\hline Complication & No. & Highest Incidence & Deaths & Comments \\
\hline Pulmonary infection & 43 & $\begin{array}{c}\text { Female, } 10-39 \text { yrs, } \\
\text { peripheral nervous } \\
\text { disease, elective }\end{array}$ & 4 & 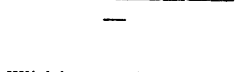 \\
\hline Displaced tube $\quad \ldots$ & 40 & $\begin{array}{l}0-9 \text { yrs, respiratory } \\
\text { disease }\end{array}$ & 2 & $\begin{array}{c}\text { Within } 48 \text { hours on } \\
30 \text { occasions, } 14 \\
\text { times severe } \\
\text { hypoxia resulted }\end{array}$ \\
\hline Structural deformity & 28 & $\begin{array}{l}\text { Respiratory and } \\
\text { peripheral nervous } \\
\text { disease, mixed } \\
\text { indications }\end{array}$ & - & $\begin{array}{l}8 \text { out of } \overline{9} \text { with deep } \\
\text { ulceration had had a } \\
\text { cuffed tube in use }\end{array}$ \\
\hline Obstructed tube $\ldots$ & 21 & $0-9$ yrs, head injury & 1 & Within 48 hours on \\
\hline $\begin{array}{l}\text { Surgical emphysema } \\
\text { and pneumothorax }\end{array}$ & 16 & $\begin{array}{l}\text { 0-9 yrs, head injury, } \\
\text { obstruction, } \\
\text { emergency }\end{array}$ & 1 & $\begin{array}{l}\text { Within few hours, } 2 \\
\text { bilateral }\end{array}$ \\
\hline $\begin{array}{l}\text { Difficult } \\
\text { decannulation }\end{array}$ & 14 & $\begin{array}{l}\text { emergency } \\
1955 \text { and } 1956,0-9 \\
\text { yrs, other trauma }\end{array}$ & - & $\begin{array}{l}\text { pneumothoraces } \\
1 \text { made permanent }\end{array}$ \\
\hline $\begin{array}{l}\text { Operative ... } \\
\text { Haemorrhage }\end{array}$ & $\begin{array}{l}14 \\
13\end{array}$ & Central nervous & $\overline{4}$ & Within few hours 9 \\
\hline Crust formation & 11 & $\begin{array}{l}\text { s-9 yrem disease } \\
0-9 \text { rs }\end{array}$ & 1 & $\begin{array}{l}\text { times } \\
\text { Often severe hypoxic }\end{array}$ \\
\hline $\begin{array}{l}\text { Miscellaneous } \\
\text { Respiratory }\end{array}$ & $\begin{array}{r}10 \\
7\end{array}$ & $\begin{array}{l}\text { Respiratory disease, } \\
\text { obstruction, } \\
\text { emergency }\end{array}$ & - & incidents \\
\hline Total & 252 & & 13 & \\
\hline
\end{tabular}

Pulmonary Infection.-This was considered to have developed only if there was no clinical or radiological evidence of pulmonary infection before tracheostomy and if signs appeared between the first and the fourth post-operative days.

Displaced Tube.-The tip of the tracheostomy tube became displaced from within the lumen of the trachea. On 29 occasions the tube was found lying out of the tracheostome, but only eight patients admitted to having pulled the tube out. The tip of the tube was also found lying in the paratracheal tissues and in the right main bronchus.

Tracheitis.-This complication, infection of the mucous membrane of the trachea in the absence of any other infection of the respiratory tract, was found only at post-mortem examination. The pathological changes ranged from mild inflammation to multiple shallow necrotic ulcers.

Structural Deformity of the Trachea.-This consisted of four separate entities-formation of granulation tissue, deep ulceration of the mucosa of the trachea at the site of the tracheostomy tube, dilatation of the lumen of the trachea, and the formation of excessive post-operative scar tissue.

Obstructed Tube.-The lumen of the tracheostomy tube became obstructed even though the tip of the tube lay within the lumen of the trachea.

Surgical Emphysema and Pneumothorax.-These are considered together, as their aetiology is probably similar, though on only five occasions did both occur at the same time.

Difficult Decannulation.-Patients failed to tolerate removal of the tracheostomy tube, and the tube had to be replaced.

Operative Complications.-These were due to surgical technique.

Haemorrhage.-This caused obstruction either by clot formation within the lumen of the trachea or tracheostomy tube, or by flooding of the lower respiratory tract through erosion of a major vessel. Four patients had also to be taken back to the theatre for control of extensive oozing of blood at the tracheostomy site.

Crust Formation.-This was not regarded as a complication in patients with acute laryngo-tracheo-bronchitis as the formation of crusts is an integral part of this disease.

Respiratory Complications.-Within two hours of tracheostomy respiration sometimes became irregular or apnoea occurred which could not be attributed to the underlying disease.
The numbers of complications in each year and in each agegroup are shown in Tables I and II ; and the numbers in each "disease on admission to hospital" and "indication" group in Table IV. These 252 complications occurred in 192 tracheostomies, an incidence of $49.3 \%$; and 13 patients died as a direct result of a complication, a mortality rate of $3.4 \%$. TABLE IV.- Number of Complications in Each "Disease on Admission
to Hospital "Group and "Indication" Group

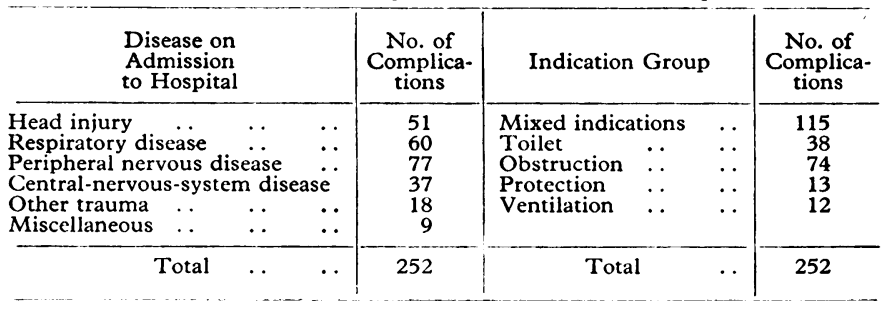

\section{Discussion}

The formidable list of complications of tracheostomy presents a frightening picture, but this must be set in perspective against the total number of tracheostomies performed and the value of the operation to each patient.

The Figure (A)-(D) shows the complications in comparison with the yearly number of tracheostomies, the age, the "disease on admission to hospittal," and the "indication" group. It will be seen that the incidence of complications was lower in the latter half of the decade, and particularly high in children, in patients with peripheral nervous disease, and when obstruction had been the indication for tracheostomy. No sex difference was noted in the incidence of complications. Emergency tracheostomies were found to have a higher complication rate than elective operations.
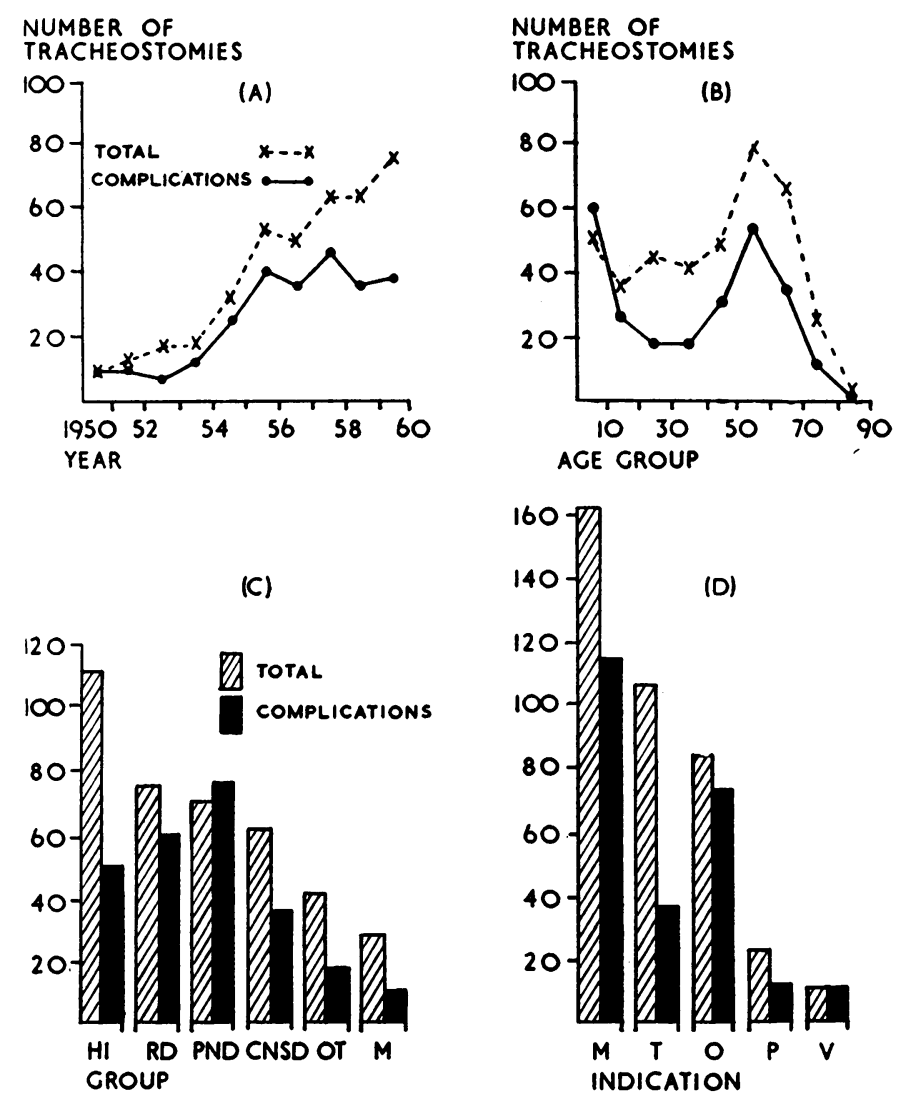

Number of complications compared with the total number of tracheostomies in each year (A), age group (B)" disease on admission to hospi- 
The value of tracheostomy was assessed for each patient in relation to the subsequent progress of the underlying disease, to complications of the tracheostomy, and to mortality. Three grades of value were distinguished: (1) the patient would have died had tracheostomy not been performed-211 (54\%); (2) the tracheostomy was of definite value to the patient and contributed materially to recovery, even if death eventually occurred as a result of the underlying disease-105 (27\%); and (3) tracheostomy was of no value in that the patient died as a result of a complication of that procedure, or the complication was a closely related cause of death, or, more usually, tracheostomy was carried out on an already moribund patient73 (19\%).

This rather arbitrary grading of tracheostomies emphasizes the value of the operation and justifies, in part, the present enthusiasm for it. However, it should be remembered that almost half the complications were infective in origin and onequarter were due to loss of a patent airway through the tracheostomy tube. In addition, many of the complications occurred in the first 48 hours after tracheostomy. It is probable, therefore, that complications could be significantly reduced by a barrier-nursing technique in a specialized unit such as an intensive therapy or respiration unit. Because of the particularly high complication rate in children the use of nasal endotracheal tubes might be considered as an acceptable alternative to tracheostomy.

\section{Summary}

In order to assess the type and incidence of complications after tracheostomy a retrospective survey was made of every tracheostomy carried out in the United Oxford Hospitals over the 10-year period 1 January 1950 to 31 December 1959 . A total of 389 tracheostomies were performed on 383 patients, and 252 complications occurred after 192 of the operationsan incidence of $49.3 \% ; 13$ deaths were directly due to the complications-a mortality rate of $3.4 \%$.

In spite of the high complication rate the value of tracheostomy outweighs the risks of these complications, the majority of which are due to infection and to loss of a patent airway.

I am grateful to Sir Robert Macintosh, Nuffield Professor of Anaesthesia, the Radcliffe Infirmary, Oxford, for helpful advice while carrying out this survey and for permission to publish these results. I also wish to thank Professor W. W. Mushin, the Welsh National School of Medicine, for his assistance with the presentation of the data.

\section{REFERENCES}

Carter, B. N., and Giuseffi, J. (1951). 7. thorac. Surg., 21, 495. Galloway, T.' C. (1943). $\tilde{f}$ Amer. med. Ass., 123, 1096. Lassen, H. C. A. (1953). Lancet, 1, 37 . Taylor, G. W., and Austin, G. M. (195i). Arch. Otolaryng., 53, 386.

\title{
Beta-haemolytic Streptococci in South-west Essex, with Particular Reference to Tetracycline Resistance
}

\author{
M. H. ROBERTSON,* M.B., CH.B., M.C.PATH.
}

\author{
Brit. med. F., 1965, 2, 569-571
}

The beta-haemolytic streptococcus has not shown the same ability to produce antibiotic- or chemotherapeutic-resistant variants as Staphylococcus aureus. In the past, however, it has shown a capacity to produce variants resistant to sulphonamide, notably in a plastic surgery unit where sulphonamide powder had been used prophylactically (Francis, 1942), and in naval establishments where a few types, after becoming resistant to sulphonamide, became predominant in populations receiving prophylactic sulphadiazine (U.S. Navy Epidemiology Unit, Number 22, 1945 ; Damrosch, 1946). None of these strains had lost their pathogenicity. Sulphonamide-resistant group A streptococci have been described in a civilian population in New York State (Johnson and Hartman, 1947).

The advent of penicillin reduced the importance of such strains, and indeed seemed almost to banish the beta-haemolytic streptococcus from Britain for many years. A survey of the antibiotic sensitivities of pathogenic organisms isolated in a large English hospital from 1951 to 1956 does not mention the beta-haemolytic streptococcus, presumably because the numbers isolated were too small (Giles and Shuttleworth, 1958), and this was my experience during the same period in Eastern Scotland. From November 1957 to April 1959 1,002 strains were isolated in the laboratories of the Northern Ireland Hospital Authority Laboratory Service (Mitchell, 1962) and 2,647 strains were isolated during eight periods of one week from 1952 to 1956 by the Public Health Laboratory Service in Eng-

* Consultant Bacteriologist, St. Margaret's Hospital, Epping, Essex. land and Wales. These isolations numbered from 569 to 213 a week (Report, 1957). During this period, however, the streptococcus was still producing small outbreaks of infection in hospitals, but only 22 epidemics of more than four cases were reported to the Public Health Laboratory Service during the period 1955 to 1958 (Williams et al., 1960). Those authors also give a list of references to these small outbreaks.

The administration of antibiotics, particularly of tetracycline, in the prophylaxis of rheumatic fever in penicillin-allergic subjects has been advocated (Hodes, 1959), and long-term therapy with tetracycline for chronic bronchitis is effective just now (Murdoch et al., 1959 ; Francis et al., 1964). This widespread use of tetracycline for respiratory infections and a noticeable increase in the numbers of beta-haemolytic streptococci being isolated, many of which were tetracycline-resistant in vitro, prompted the present communication.

Tetracycline-resistant streptococci have been reported from many parts of the world, notably in a special burns unit in England where a chlortetracycline-resistant group A streptococcus was observed to arise during the course of treatment (Lowbury and Cason, 1954), and, again in the same unit, an atypical anaerobic form, designated $\mathrm{AN}$, associated with tetracycline-resistance, was described (Lowbury and Hurst, 1956). Of more serious import were an outbreak of pharyngitis in New Orleans due to a tetracycline-resistant variant (Mogabgab and Pelon, 1958) and a report of tetracycline failure in the treatment of streptococcal pharyngitis due to tetracyclineresistance in New York (Stillerman et al., 1960). The presence 